University of Nebraska - Lincoln

DigitalCommons@University of Nebraska - Lincoln

2013

\title{
Army Flight Medic Performance Of Paramedic Level Procedures: Indicated Vs. Performed
}

Scott A. Bier

U.S. Army Medical Corps

Erik Hermstad

U.S. Army Medical Corps

Christopher Trollman

U.S. Army Medical Corps

Melinda Holt

Sam Houston State University

Follow this and additional works at: https://digitalcommons.unl.edu/usarmyresearch

Bier, Scott A.; Hermstad, Erik; Trollman, Christopher; and Holt, Melinda, "Army Flight Medic Performance Of Paramedic Level Procedures: Indicated Vs. Performed" (2013). US Army Research. 184.

https://digitalcommons.unl.edu/usarmyresearch/184

This Article is brought to you for free and open access by the U.S. Department of Defense at DigitalCommons@University of Nebraska - Lincoln. It has been accepted for inclusion in US Army Research by an authorized administrator of DigitalCommons@University of Nebraska - Lincoln. 


\title{
Selected Topics:
} Aeromedical Emergency

\section{ARMY FLIGHT MEDIC PERFORMANCE OF PARAMEDIC LEVEL PROCEDURES: INDICATED VS. PERFORMED}

\author{
Scott A. Bier, MD, ${ }^{\star}$ Erik Hermstad, MD,† Christopher Trollman, Do, $\ddagger$ and Melinda Holt, PHD§ \\ *U.S. Army Medical Corps, Department of Emergency Medicine, 4th Combat Aviation Brigade, Fort Hood, Texas, †U.S. Army Medical Corps, \\ Department of Emergency Medicine, William Beaumont Army Medical Center, Fort Bliss, Texas, łU.S. Army Medical Corps, 159th Combat \\ Aviation, Fort Campbell, Kentucky, and §Department of Mathematics and Statistics, Sam Houston State University, Huntsville, Texas \\ Corresponding Address: Scott A. Bier, MD, U.S. Army Medical Corps, Department of Emergency Medicine, 4th Combat Aviation Brigade, \\ Fort Hood, TX 77380
}

Abstract-Background: There is great disparity in the education, experience, and staffing requirements for civilian and Army aeromedical transports (AMT). Objective: This study sought to determine if medical skills beyond the standard training for Army flight medics were indicated and being performed on Army AMT missions. As a secondary measure, the percentage of indicated interventions performed by basic Emergency Medical Technician (EMT-B) and paramedic (EMT-P) flight medics were compared. Methods: This was a retrospective review of Army AMT charts including patients transported by an EMT-B-staffed unit in Iraq and an EMT-P-staffed unit in Afghanistan from July 2008 to June 2009. Charts were reviewed independently by two Emergency Medicine board-certified Army flight surgeons. Results: Of 984 interventions found to be indicated on the 406 charts that met inclusion criteria, $36 \%$ were rated as EMT-P level. Seventeen percent were

Prior publication/presentation: Poster presentations at Government Services American College of Emergency Physicians (ACEP) Symposium, San Antonio, TX, March 2011, and at ACEP Scientific Assembly, San Francisco, CA, October 2011, with abstract published in Annals of Emergency Medicine supplemental section, October 2011 (2011;58:S299).

Disclaimer: The opinions or assertions contained herein are the private views of the authors and are not to be construed as official or as reflecting the views of the Department of the Army or the Department of Defense.

Reprints are not available from the authors. indicated but not performed. EMT-Bs failed to perform indicated procedures $35 \%$ of the time vs. $3 \%$ in the EMT-P group $(p<0.001)$. For paramedic-level procedures, EMTBs failed to make $76 \%$ of appropriate interventions, compared to $<1 \%$ in the EMT-P group $(p<\mathbf{0 . 0 0 1})$. Conclusions: There seems to be a substantial number of procedures beyond the scope of standard Army flight medic training being required for Army AMT missions. It seems that when advance interventions are indicated, those trained to the EMT-P level perform them significantly more often than those trained to Army standard. Conclusions: Based on the findings of this study, the authors suggest the Army consider adopting the standards required for civilian AMT. Published by Elsevier Inc.

Keywords-military medicine; emergency medical services; air ambulance

\section{INTRODUCTION}

Every day, hundreds of United States (US) Army medical evacuation unit (MEDEVAC) missions are launched from bases all over the world. The HH-60 Blackhawk used for these missions is a state-of-the-art airframe, and is piloted by some of the most skilled and experienced pilots in the world. The reliability of Army MEDEVAC is second to none. In fact, it has been suggested that when it comes to safety, the civilian aeromedical transport (AMT) community could learn a great deal from the Army system (1). 
Unfortunately, it has also been suggested that the Army falls well short of civilian standards when it comes to the training of their medical providers (2).

Army combat medics begin their training with a rigorous 17-week course at Fort Sam Houston in San Antonio, Texas. During the first half of this course they are trained and certified to the National Registry of Emergency Medical Technicians (NREMT) basic standard (EMT-B). The second half of this course concentrates on trauma management as well as advanced skills including intravenous line placement and limited airway management. Although they are certified by the NREMT to only the EMT-B level, with the additional skills they are taught as part of their initial training, standard Army combat medics operate at a level comparable to civilian Advanced Emergency Medical Technicians (AEMT). In most cases, combat medics must gain some experience through assignment to either a hospital or line unit before they are eligible to apply for the flight medic course, which consists of 4 weeks of training at Fort Rucker, Alabama. During this course, students complete Advanced Cardiac Life Support, Pediatric Education for Prehospital Professionals, Prehospital Trauma Life Support, and aeromedical physiology training. Although this course does provide some advanced training, it does not approach the depth or scope of a paramedic program (2).

Due to the increased operational tempo imposed on the Army over the past decade and the shortage of trained flight medics, some receive on-the-job training from their individual unit without attending the official course. It should be noted that in the combat environment, the guidelines that govern Army medics' scope of practice is less stringent than their civilian counterparts, allowing them to operate beyond their NREMT level of training when required. Once trained, there is no standard continuing education requirement other than to maintain their EMT-B certification. Army flight medics (AFM) will often go months without seeing patients when not in the deployed environment.

In addition to one flight medic and two pilots, the standard crew for an Army MEDEVAC mission also includes a crew chief. Crew chiefs are trained as Combat Life Savers, an Army certification which is approximately equivalent to a civilian first responder. In addition to aiding the flight medic, crew chiefs are also responsible for a host of other essential flight-related responsibilities. This is in stark contrast to the standard flight crew of civilian AMTs, which are generally staffed by two dedicated medical attendants whose sole responsibility is the care of their patients. Additionally, although there is some debate as to the optimal level of training for an AMT provider, it is standard of care for civilian transports that they are staffed either by paramedics, nurses, or physicians (1).
Because there is some question as to what the appropriate level of training should be to prepare AFM for the transport and care of high-acuity patients, we sought to determine if medical interventions beyond their standard scope of training were indicated on Army AMT missions. As a secondary measure we evaluated the percentage of indicated paramedic procedures actually performed and compared that percentage between a group of EMT-B and paramedic (EMT-P) trained flight medics in the deployed environment.

\section{MATERIALS AND METHODS}

This study was a retrospective chart review based on Army MEDEVAC missions conducted between July 2008 and June of 2009. Data were collected from the Combat Aviation Brigades of the Fourth Infantry Division deployed in Iraq and the Hundred and First Airborne Division deployed in Afghanistan. Two different MEDEVAC companies were included to minimize bias that may have resulted from education provided to medics by their medical directors or injury patterns observed within a particular combat theater. The sample obtained from the Iraq-based MEDEVAC Company was exclusively comprised of EMT-B-level AFM, whereas the Afghanistanbased medics were exclusively EMT-P trained. To obtain the population most likely to require medical interventions, charts were prescreened to include only those in the "urgent" and "urgent surgical" categories, excluding the lower-acuity "priority," "routine," and "convenience" categories. This classification system serves as a triage to determine order of evacuation, with urgent and urgent surgical patients being defined as those requiring medical or surgical attention, respectively, within $2 \mathrm{~h}$ to preserve life, limb, or eyesight (3). Both medical and trauma patients were included for review in this study. Charts in which patient care was not completely documented, contained insufficient information in general, or were inappropriately categorized based on their severity were also excluded from this study.

Demographic information was collected, including age, sex, nationality, number of patients on board, and injury/illness patterns. Runs were also evaluated to determine if the AFM was aided by either the crew chief or an advanced-level provider (physician, physician assistant, nurse). If an intervention was noted as having been performed by an advanced-level provider, the procedure was not included as part of the study. Vital signs and Glasgow Coma Scale score were also recorded to calculate a Revised Trauma Score (RTS) for each chart. A data collection tool was created to analyze charts and record the level of necessary interventions dictated by a patient's condition. Raters determined interventions to be indicated if they would have been expected as standard of 
care for a prehospital provider. Interventions were divided into EMT-B, AEMT, or EMT-P categories based on the NREMT training standards and National Emergency Medical Services Education Standards recommendations (Table 1) $(4,5)$. Charts were then reviewed to determine if medical interventions that were indicated were actually performed. If an intervention was not made but deemed by the reviewers to be within the scope of prehospital care and could have reasonably been performed in an AMT environment, it was noted as a failure to execute. Likewise, if a procedure was not indicated but performed anyway, it was recorded as an over-treatment.

Transports were also categorized as critical care or non-critical care according to the Commission on Accreditation of Aeromedical Transport Systems' definition (6). Examples include transports during which flight medics were performing lifesaving interventions that prevented them from tending to other patients, active ventilator or chest tube management, and cardiac or traumatic arrests. This categorization was done to provide a separate measure of patient acuity independent of the Army's "urgent" or "urgent surgical" designation.

Each chart was evaluated subjectively by two boardcertified Emergency Medicine physicians with prehospital care experience who had also served as Army Flight Surgeons. Chart evaluations were based on the rater's training and experience. If a discrepancy occurred between raters on a particular record it was counted as a negative result, thus decreasing the chance for interrater reliability issues. For example, if one rater deemed an intervention to be indicated while the other did not, the intervention was not recorded as being indicated. After data were compiled, they were analyzed using SPSS (IBM, Armonk, NY) and Microsoft Excel (Microsoft Corporation, Redmond, WA) under the supervision of a statistician. This study was conducted under a protocol reviewed and approved by the US Army Medical Research and Materiel Command Institutional Review Board, and in accordance with the approved protocol. It was also approved by the offices of the Multinational Corp Iraq Surgeon and the Combined Joint Task Force 101 Surgeon, Afghanistan.

\section{RESULTS}

Of the 466 total charts reviewed from both MEDEVAC companies, a total of 406 met inclusion criteria, 224 from the Iraq-based unit and 182 from the Afghanistanbased unit (Table 2). It should be noted that due to electronic data storage issues, 40 of the charts from the Afghanistan arm of this study were lost before being evaluated by both reviewers and were therefore excluded from the study. A total of 20 other charts were excluded from the study based on failure to meet the stated inclusion criteria.

The age of those transported ranged from 2.5 to 65 years; the average age was 28 years old ( $s=1.5$ years).

Table 1. Medic Interventions by Skill Level $(4,5)$

\begin{tabular}{|c|c|c|}
\hline EMT-B Skills & AEMT Skills & EMT-P Skills \\
\hline $\begin{array}{l}\text { Basic Life Support/CPR } \\
\text { Automated external defibrillator use } \\
\text { Automatic transport ventilator use } \\
\text { (passive) } \\
\text { Bag-valve mask ventilation } \\
\text { Upper airway adjunct insertion } \\
\text { Upper airway suction } \\
\text { Supplemental oxygen administration } \\
\text { Spinal immobilization } \\
\text { Fracture/dislocation immobilization } \\
\text { Traction splinting } \\
\text { Bleeding management } \\
\text { Assist patient taking own medications } \\
\text { Aspirin for suspected ischemic chest pain } \\
\text { Tourniquet for uncontrolled bleeding } \\
\text { Placement of hemostatic wound dressing } \\
\text { Oral glucose for hypoglycemia }\end{array}$ & $\begin{array}{l}\text { Establishing peripheral i.v. } \\
\text { Establish/maintain intraosseous line } \\
\text { Intravenous fluid therapy } \\
\text { Administer sublingual nitroglycerin } \\
\text { Epinephrine for anaphylaxis } \\
\text { Administer intravenous D50 } \\
\text { Blood glucose monitor } \\
\text { Tracheobronchial suctioning intubated } \\
\text { patient } \\
\text { Insertion of dual-lumen airway device } \\
\text { Administer opioid antagonist } \\
\text { Administer inhaled beta-agonist } \\
\text { Administer glucagon }\end{array}$ & $\begin{array}{l}\text { 12-lead ECG/cardiac monitor } \\
\text { interpretation } \\
\text { Blood chemistry analysis } \\
\text { Blood sampling } \\
\text { Access indwelling catheters/central i.v. } \\
\text { ports } \\
\text { Thrombolytic initiation } \\
\text { Medications not previously mentioned } \\
\text { Managing i.v. infusions } \\
\text { Establish i.o. access (adult) } \\
\text { Oral and nasal endotracheal intubation } \\
\text { Laryngeal mask airway } \\
\text { Bi-PAP, CPAP, PEEP } \\
\text { Cricothyroidotomy } \\
\text { Chest tube monitoring } \\
\text { End-tidal carbon dioxide monitoring } \\
\text { Decompress the pleural space } \\
\text { Place naso-/orogastric tube } \\
\text { Maintain an infusion of blood/blood } \\
\text { products } \\
\text { Cardioversion/defibrillation } \\
\text { Transcutaneous pacing } \\
\text { Carotid massage }\end{array}$ \\
\hline
\end{tabular}

EMT-B = basic Emergency Medical Technician; AEMT = advanced Emergency Medical Technician; EMT-P = paramedic Emergency Medical Technician; CPR = cardiopulmonary resuscitation; i.v. = intravenous; $\mathrm{ECG}$ = electrocardiogram; i.o. = intraosseous; $\mathrm{Bi}-\mathrm{PAP}=$ bi-level positive airway pressure; CPAP = continuous positive airway pressure; PEEP = positive end-expiratory pressure. 
Table 2. Demographics

\begin{tabular}{|c|c|c|c|}
\hline & Total & Iraq (EMT-B group) & Afghanistan (EMT-P group) \\
\hline Charts Reviewed & 406 & 224 & 182 \\
\hline \multicolumn{4}{|l|}{ MEDEVAC category } \\
\hline Urgent & $256(63 \%)$ & 166 (74\%) & $90(49 \%)$ \\
\hline Urgent Surgical & $150(37 \%)$ & $58(26 \%)$ & $92(51 \%)$ \\
\hline \multicolumn{4}{|l|}{ Age } \\
\hline Average & $28(s=11.5)$ & $30(s=10.75)$ & $27(s=9)$ \\
\hline Median & 26 (IQR 13.75) & 27 (IQR 14) & 25 (IQR 10) \\
\hline Pediatric patients & $33(8 \%)$ & $7(3 \%)$ & $26(14 \%)$ \\
\hline \multicolumn{4}{|l|}{ Sex } \\
\hline Male & $371(91 \%)$ & 203 (91\%) & 168 (92\%) \\
\hline Female & 35 (9\%) & 21 (9\%) & $14(8 \%)$ \\
\hline \multicolumn{4}{|l|}{ Call type } \\
\hline Medical & $103(25 \%)$ & $72(32 \%)$ & $31(17 \%)$ \\
\hline Trauma & $303(75 \%)$ & $152(68 \%)$ & $151(83 \%)$ \\
\hline AMT with advanced provider assistance & $20(5 \%)$ & $9(4 \%)$ & $11(6 \%)$ \\
\hline AMT with crew chief assistance & $37(9 \%)$ & $32(14 \%)$ & $5(3 \%)$ \\
\hline AMT with multiple patients & $86(21 \%)$ & $32(14 \%)$ & $54(30 \%)$ \\
\hline
\end{tabular}

EMT-B = basic Emergency Medical Technician; EMT-P = paramedic Emergency Medical Technician; IQR = interquartile range; $\mathrm{AMT}=$ aeromedical transport.

Thirty-three of the charts reviewed for this study involved pediatric patients, and the overwhelming majority of those transported were male (91\%). Of the 406 transports, $5 \%$ had a higher-level provider on board, and the flight medic noted receiving assistance from the crew chief in $9 \%$ of cases. Assuming no overlap between calls where assistance was rendered from the crew chief or a higher-level provider, a single flight medic was therefore the sole medical attendant in $86 \%$ of transports. Twenty-one percent of runs involved multiple patients. On-scene time ranged from 1 to $131 \mathrm{~min}$, with a mean of 13 and a median of $8 \mathrm{~min}$. Transport time ranged from 1 to $52 \mathrm{~min}$, with mean of 17 and a median of 11 min. Average total patient contact time was $19 \mathrm{~min}$, but ranged from 2 to $183 \mathrm{~min}$.

When analyzing which charts met critical care criteria, the reviewers agreed on $91 \%$ of cases $(\kappa=0.77)$. The remaining 38 on which there was disagreement were not included in this part of the statistical analysis. Of the charts that were included, $24 \%(n=89)$ were rated as critical care transports. In comparing the two study locations, the Iraq group was found to have $20 \%$ critical care transports, compared to Afghanistan, which had 29\% $(p=0.05)$. RTS scores between the two MEDEVAC Companies were found to be similar, both with an average of 10.5 .

As would be expected in a combat zone, the vast majority of transports resulted from traumatic rather than medical etiologies (303 trauma vs. 103 medical). The most common mechanisms of injury noted in this study included blast injuries, followed by blunt and penetrating trauma (Figure 1), whereas the most frequent cause for transport due to medical ailments was cardiac and abdominal issues (Figure 2). It should be noted that some patients sustained multiple injuries, and therefore, there exists some overlap in injury patterns. The most commonly injured body part was the head (27\%), followed by the thorax $(23 \%)$ and then the lower $(21 \%)$ and upper extremities $(21 \%)$.

After reviewing the 406 charts that met inclusion criteria, raters agreed that 984 procedures were indicated, of which 168 were not performed (17\%). Two procedures total $(<1 \%)$ were performed but not indicated. Of those not performed, 48 were considered to be paramedic level, accounting for $13.6 \%$ of the 356 paramedic procedures indicated. The most common missed intervention overall was insertion of intravenous lines/administration of intravenous fluids (Table 3). Of the indicated procedures, $36 \%$ were rated as being consistent with paramedic-level skills (Table 4). The most common paramedic procedures performed included medicine administration, cardiac

\section{Miscellaneous
$5 \%$ Trauma}

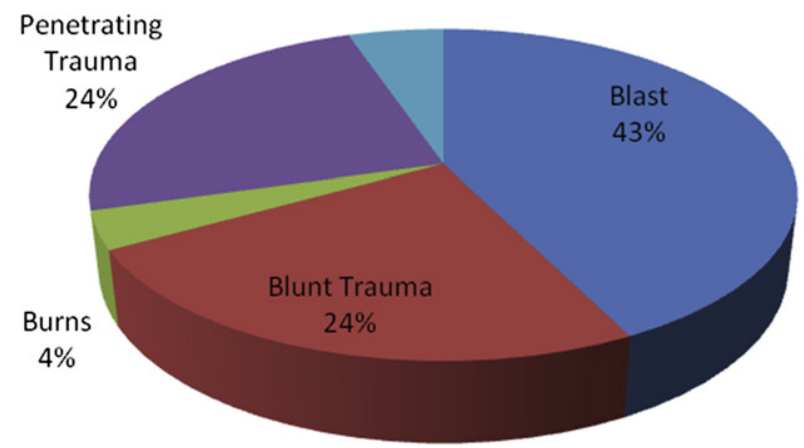

Figure 1. Trauma: mechanism of injury/illness. 


\section{Medical}

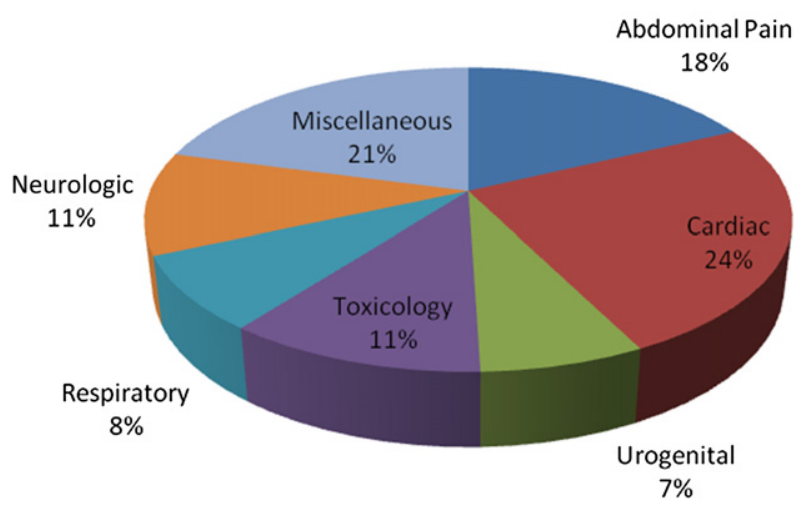

Figure 2. Medical: mechanism of injury/illness.

monitoring, and ventilator management (Figure 3), and the most common basic/AEMT interventions performed were oxygen administration, fluid bolus, and intravenous line placement (Figure 4). When medicines were administered, the most frequent ones were, in descending order, analgesics, sedatives, paralytics, and anti-emetics.

Subgroup analysis was performed to determine if any differences existed between the EMT-B and EMT-P groups. Overall, EMT-Bs failed to perform indicated procedures $35 \%$ of the time, vs. only $3 \%$ in the EMT-P group $(p<0.001,95 \%$ confidence interval [CI] 28-42\%). When this comparison is made using only paramedic-level procedures, EMT-Bs failed to make $76 \%$ of indicated interventions, compared to $<1 \%$ in the EMT-P group $(p<0.001,95 \%$ CI $69-81 \%)$.

\section{DISCUSSION}

Since its humble beginnings over 50 years ago during the Korean War, the military has led the way in AMT. As discussed earlier, this is still the case with airframe, mainte-

Table 3. Indicated Interventions Not Performed

\begin{tabular}{lccc}
\hline & Overall & $\begin{array}{c}\text { Iraq Group } \\
\text { (EMT-B) }\end{array}$ & $\begin{array}{c}\text { Afghanistan } \\
\text { Group (EMT-P) }\end{array}$ \\
\hline $\begin{array}{l}\text { Intravenous access/fluid } \\
\quad \text { administration }\end{array}$ & 84 & 72 & 12 \\
Cardiac monitoring & 28 & 27 & 1 \\
$\begin{array}{l}\text { Oxygen administration } \\
\text { Advanced airway }\end{array}$ & 16 & 11 & 5 \\
$\quad$ management & 9 & 9 & 0 \\
Medicine administration & 8 & 8 & 0 \\
Nasopharyngeal airway & 5 & 5 & 0 \\
Splinting & 5 & 5 & 0 \\
Rapid sequence induction & 4 & 4 & 0 \\
Needle thoracostomy & 3 & 3 & 0 \\
Other & 4 & 4 & 0 \\
Totals & 166 & 148 & 18 \\
\hline
\end{tabular}

EMT-B = basic Emergency Medical Technician; EMT-P = paramedic Emergency Medical Technician. nance, and safety. It seems that over the last two decades, however, the Army has fallen behind their civilian counterparts in the training, education, and experience of their flight medics. Most authorities agree that the EMT-B skill level of the typical Army flight medic makes them less capable than their more highly trained counterparts in the management of critically ill or injured patients. Although there is some debate as to the appropriate configuration of physician, nurse, and paramedic on AMTs, virtually all civilian programs fly with two such crewmembers (1).

The primary focus of this study was to determine if paramedic-level procedures were required by the mission of AFM in Iraq and Afghanistan. After reviewing 406 charts from two Army MEDEVAC companies, a total 354 of these interventions were found to be indicated. These findings are concerning, as AFMs are only trained to the EMT-B level, with a small amount of extra training that is often variable. This raises the important question of whether the current standard of training for AFMs causes them to work outside their scope of practice to care for critically ill patients in the deployed environment.

Many of the AMTs evaluated in this study involved transport from remote medical facilities to larger Combat Support Hospitals after stabilization surgery. It is interesting to note that some of the most common paramediclevel procedures involved management of these patients, many of which were transported on ventilators $(5.4 \%)$ or with thoracostomy tubes (1.2\%). In fact, $40 \%$ of all medicine administration was for paralytics or sedatives, most of which were utilized in the care of these patients. With average transport times in the more spread-out Afghan theater approaching $30 \mathrm{~min}$, and the longest transports taking greater than an hour, it is alarming to consider that these critically ill and medically complicated patients are being cared for at times by medics trained only to the EMT-B level.

The secondary objective of this study was to determine if indicated procedures were being performed and if there was a difference in the completion rate between those trained to the EMT-B and EMT-P levels. The data indicate that a large number of indicated paramedic level procedures were not performed (4.9\%, or 48 of the 984 total indicated procedures), suggesting that a lack of training and experience may be responsible for the undertreatment of patients cared for by AFMs. Additionally, there was a significant difference between the EMT-B and EMT-P subgroups in completion of indicated paramedic-level procedures. This seems to imply that the extra training and education afforded to these more highly trained AFMs better enabled them to perform indicated interventions when treating their patients.

One of the interesting findings of this study was the large number of non-traumatic transports. Although the vast majority of AMTs are for traumatic injuries, $25 \%$ 
Table 4. Indicated vs. Performed

\begin{tabular}{|c|c|c|c|c|c|}
\hline \multicolumn{6}{|c|}{ Paramedic Level Procedures } \\
\hline \multicolumn{2}{|c|}{ Overall } & \multicolumn{2}{|c|}{ Iraq (EMT-B) } & \multicolumn{2}{|c|}{ Afghanistan (EMT-P) } \\
\hline Indicated & 354 & Indicated & 63 & Indicated & 291 \\
\hline Performed & 305 (86.2\%) & Performed & 15 (23.8\%) & Performed & 290 (99.7\%) \\
\hline Not performed & 48 (13.6\%) & Not performed & 47 (74.6\%) & Not performed & $1(0.3 \%)$ \\
\hline Not indicated & $1(0.3 \%)$ & Not indicated & $1(1.6 \%)$ & Not indicated & $0(0.0 \%)$ \\
\hline
\end{tabular}

EMT-B = basic Emergency Medical Technician; EMT-P = paramedic Emergency Medical Technician.

of runs were found to be due to medical illnesses. Additionally, $8 \%$ of transports in cases reviewed were for pediatric patients. Recently, an experienced AFM in Afghanistan commented, "If it's trauma we're goodto-go, but not if it's medication, disease, illness or pediatrics" (7). The need for flight medics to possess comprehensive medical training is further underscored by a 2005 study that assessed the demographics of aeromedical evacuation from Operation Iraqi Freedom. They found that $86.5 \%$ of the 11,183 evacuated were classified as "Disease Non Battlefield Injuries" and 68.4\% were transported for non-surgical reasons, suggesting they were non-traumatic in nature (8).

In a 2008 article, Captain Joseph Madill suggested that there was an Army-wide deficiency in the training of AFM (7). Serving as a Flight Surgeon in Afghanistan at the time, Madill stated that the flight medics in the MEDEVAC Company he was assigned to were being called upon to perform paramedic-level interventions, including rapid sequence induction, ventilator management, and pediatric life support. He went on to say that because his unit's flight medics were only trained to the EMT-B level, they had little training or meaningful exposure to these complicated, advanced-level procedures. In a separate article describing the role and capabilities of Army MEDEVAC, National Guard Sergeant R. A. Higgins, who also has served as a civilian fire-based and flight paramedic, stated that the greatest

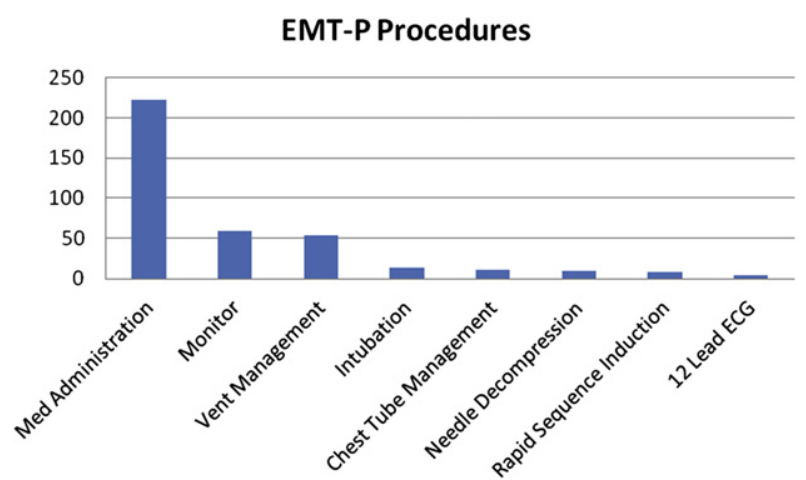

Figure 3. Most common paramedic-level interventions. EMT-P = paramedic Emergency Medical Technician; ECG = electrocardiogram. challenge of his career was performing as an AFM in Afghanistan (2).

\section{Limitations}

Some of the limitations of this study included lack of blinding to the AFM's training level, absence of outcome data, and the variability of individual MEDEVAC unit medical training. Blinding was not possible, as the two different units used different charting systems that automatically informed the reviewer of the AFM's level of training. Although there was not a reliable collection system to track outcome data from the point of injury/illness back to the home station, these systems have greatly improved since the time this research was conducted. Follow-up to this pilot study should therefore be conducted to address the issue of clinical outcomes to determine if performance of these prehospital procedures provides benefit to the patient. Finally, our research did not take into account unit-specific training as a possible confounding factor. This training depends on several aspects, including experience of the unit's medical director/senior medics as well as command climate, and can differ greatly from unit to unit.

\section{CONCLUSIONS}

Most would agree that the mission and scope of military and civilian AMT is very different, which makes it

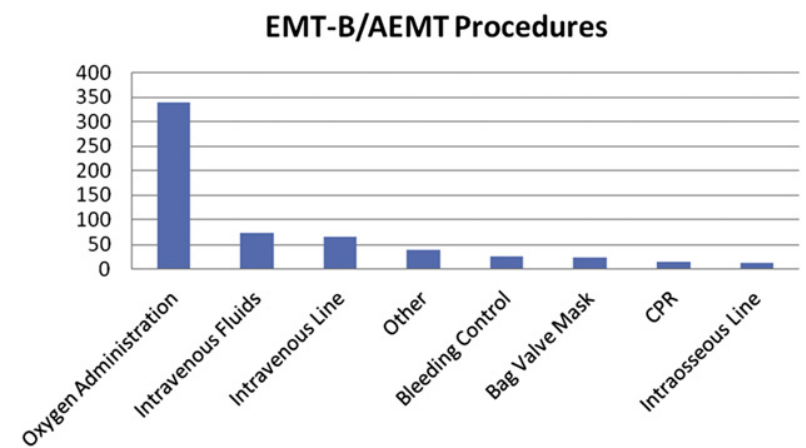

Figure 4. Most common basic/AEMT-level interventions. EMT-B = basic Emergency Medical Technician; AEMT = advanced Emergency Medical Technician. 
difficult to make direct comparisons. Standards of medical care, however, should remain consistent in both arenas, whether the patient being transported is a civilian involved in a motor vehicle accident on a rural road in the Midwest or an American soldier struck by shrapnel from an improvised explosive device in Afghanistan. This research suggests that there are a substantial number of critical care transports and paramedic-level procedures being performed on AMT missions in the deployed environment. Furthermore, it seems that when these advanced interventions are indicated, those trained to the EMT-P level are performing them significantly more often than those trained to Army standard. Fortunately, a call for more advanced flight medic training based on lessons learned from the wars in Iraq and Afghanistan has resulted in the planned implementation of a new advanced training program (9). This year, the Army Medical Department Center and School will launch a three-phase program which, in addition to the current flight medic training, will also include a 6-month paramedic program and 8-week critical care transport course. As Colonel Richard Gerhardt once said, "The U.S. Army MEDEVAC community has established a tradition of excellence to be both treasured and maintained. There also exists an unwritten bond of trust between the Army Medical Department and the troops we send into harm's way, that we will provide them with the best and most modern care that we can provide" (10).

Acknowledgments - The authors would like to acknowledge Ltc. Scott Orr, MD, Maj. Brendan McCriskan, MD, and Sgt.
Michael Ferguson for their contributions to this study. A special thanks to all the brave men and women of the US Army MEDEVAC who risk their lives every day to "conserve the fighting strength.” Dustoff!

\section{REFERENCES}

1. De Lorenzo R. Military and civilian emergency aeromedical services: common goals and different approaches. Aviat Space Environ Med 1997;68:57-60.

2. Higgins R. MEDEVAC: critical care transport from the battlefield. AACN Adv Crit Care 2010;21:288-97.

3. Pizzola J. MEDEVAC miscategorization. Mil Med 2010;175: $655-8$.

4. The National Highway Traffic Safety Administration. National EMS scope of practice model; February 2007. National Registry of Emergency Medical Technicians Web site. Available at: https://www. nremt.org/nremt/downloads/Scope\%20of\%20Practice.pdf. Accessed March 15, 2009.

5. The National Highway Traffic Safety Administration. National emergency medical services education standards; January 2009. EMS.gov Web site. Available at: http://ems.gov/pdf/811077a.pdf. Accessed March 2, 2011.

6. Commission on Accreditation of Medical Transport Systems. $8^{\text {th }}$ Edition accreditation standards of the Commission on Accreditation of Medical Transport Systems. Available at: http://www.camts.org/ component/option,com_docman/task,cat_view/gid,17/Itemid,44/. Accessed September 15, 2011.

7. Cearnal L. Emergency physicians highlight, "Army-wide emergency medical care deficiency" in training of flight medics. Ann Emerg Med 2008;52:522-4.

8. Harman D, Hooper T, Gackstetter G. Aeromedical evacuations from Operation Iraqi Freedom: a descriptive study. Mil Med 2005;170: $521-7$.

9. Tougher, longer training in store for flight medics. Army Times 2011 June;p.23.

10. Gerhardt R, McGhee J, Cloonan C, Pfaff JA, De Lorenzo RA. US Army MEDEVAC in the new millennium: a medical perspective. Aviat Space Environ Med 2001;72:659-64. 


\section{Why is this topic important?}

\section{ARTICLE SUMMARY}

This topic addresses a potential deficiency in the training level of flight medics in what is most likely the largest MEDEVAC service in the world responsible for the evacuation and medical care of thousands of people per year. If this decreased level of training and experience vs. their civilian counterparts results in suboptimal care, it would indeed be a major finding.

\section{What does this study attempt to show?}

This study attempts to determine whether there are a substantial number of paramedic-level procedures indicated on Army MEDEVAC missions and when they are indicated, if those with higher than standard-level training are performing them more frequently.

\section{What are the key findings?}

The key finding of this study is that there are numerous paramedic-level procedures indicated on Army MEDEVAC missions for which the standard flight medic is not formally trained to perform. Another important finding is that when these procedures are indicated, those medics trained to the paramedic level perform them a significantly higher percentage of the time. A final finding is that a considerable number of these missions are of a medical rather than traumatic nature, an area that standard Army flight medic training does not concentrate on.

\section{How is patient care impacted?}

Although our data cannot show a direct impact on patient outcomes, they can show that on many missions, Army flight medics are not performing up to the general standards set by National Registry of Emergency Medical Technicians/National EMS Education Standards for EMS providers. If medical interventions are beyond the scope of practice of the practitioner and indicated procedures are not being performed in accordance with usual prehospital standards, it can be inferred that the lack of training and experience in Army flight medics might be contributing to an increase in morbidity and mortality of those transported. 